\title{
Time utilization and spending pattern of fisher women in house hold task and subsidiary occupation
}

\author{
HEMANT JADHAV AND GIRISH DESHMUKH
}

Received: 27.05.2014; Revised: 07.10.2014; Accepted: 20.10 .2014

See end of the paper for authors' affiliations

\section{GIRISH DESHMUKH}

Junagadh Agricultural University, JUNAGADH (GUJARAT) INDIA Email: 251girish@gmail.com
ABSTRACT : The extend of participation of women in fish related activities varies from country depending on the local conditions, level of literacy, social customs and economic conditions of states generally involves fish drying, processing, loading and unloading, retail marketing and net making. Marketing is one of the important aspects in fisheries, which is basically looked after by fisherwomen. Time is a unique and valuable resource. Women spend a lot of time not only in managing their homes but also managing their farms and animals, but most of the time their contribution remains unrecognized. Therefore, an attempt was made to know the time spent pattern of fisher women in fishing operation. The data in this regards were collected through interview using 24 hours recall method. Ten different house hold activities were identified related to household work in which fisher women were engaged daily, weekly and seasonal work.

KEY WORDS: Fisherwomen, Time utilization, House hold task

- HOW TO CITE THIS PAPER : Deshmukh, Girish and Jadhav, Hemant (2014). Time utilization and spending pattern of fisher women in house hold task and subsidiary occupation. Asian J. Home Sci., 9 (2) : 473-476. 